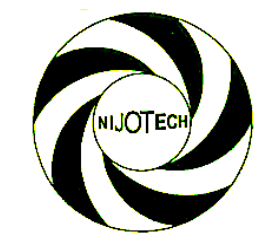

Nigerian Journal of Technology (NIJOTECH)

Vol. 39, No. 3, July 2020, pp. 871 - 886

Copyright(C) Faculty of Engineering, University of Nigeria, Nsukka,

Print ISSN: 0331-8443, Electronic ISSN: 2467-8821 www.nijotech.com

\title{
ANALYSIS AND IMPLEMENTATION OF A SOLAR TRACKING
} RACK SYSTEM

\author{
A. A. Okandeji ${ }^{1}{ }^{*}$, M. B. Olajide ${ }^{2}$, G. O. Olasunkanmi ${ }^{3}$ and Z. O. Jagun ${ }^{4}$ \\ 1, Department of Electrical and EleCtronic ENGINEERING, Univ. OF LAGOS, AKOKA, LAGOS StATE, NIGERIA

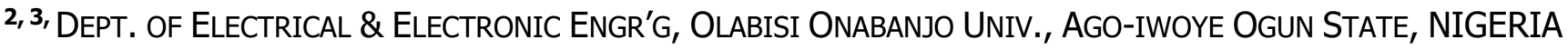 \\ 4, DePt of Computer Engineering, Olabisi OnABANJo University, AGO-IWOYE, OGUn STATE, NIGERIA \\ Email addresses: ${ }^{1}$ aokandeji@unilag.edu.ng; ${ }^{2}$ olajide.mathew@oouagoiwoye.edu.ng, \\ 3 grace.olasunkanmi@oouagoiwoye.edu.ng; ${ }^{3}$ jagun.zaid@oouagoiwoye.edu.ng
}

\begin{abstract}
Solar energy is the most feasible source of renewable energy especially in sun rich regions like Africa. In particular, electrically epileptic country like Nigeria with current power output of only about 3.5GW of energy has a relatively long sunny period for about $90 \%$ of the year, making Nigeria very rich in solar power. Maximally harnessing solar energy into usable electricity however, is still a fundamental problem as the existing models can harness only about $70 \%$ of the available energy. To maximally harness solar energy, a solar panel must be perpendicular to the energy source for all 12 hours of sunlight availability, and must be able to follow the sun's movement all day long. Accordingly, this work considers the analysis, construction, and implementation of a single axis solar tracking dynamic system. Experimental result show that the proposed system outperforms the conventional static solar tracking system.
\end{abstract}

Keywords: solar energy, single axis, harvesting-solar energy.

\section{INTRODUCTION}

Solar Energy is a typical form of renewable unlimited energy. The radiation is produced by nuclear fusion reactions deep in the Sun's core. The Sun provides almost all the heat and the light Earth receives, and therefore sustains every living being. Technological advancement has made it possible to harvest this energy and transform its crude state into more diverse forms for diverse utilization which could be categorized into; Indirect collection of solar energy, and direct collection of solar energy. For over a decade, harnessing solar energy has been critical particularly due to the depletable, expensive and pollution characteristics of fossil fuels. Accordingly, solar energy has strong potentials to play a great future role for energy sustainability globally. Substantial effort has therefore been made to cover numerous issues associated with harnessing solar power. Authors in [16] have highlighted various characteristics for harnessing solar energy. Some of these characteristics include; the prediction of the optimum angle of inclination for flate plate solar collector, time of the day, distance from the sun, intensity of the sun amongst others. However, the consideration of these factors have only been able to harness 70 percent of the available solar energy. To maximally harness solar energy, a solar panel must be perpendicular to the energy source for sunlight availability, and must be able to track the sun's movement all day long to produce highest efficiency [7]. In contrast to existing results, this work considers a novel analysis, construction, and implementation of a frame work to carry out this positioning task in order to maximally harvest solar energy. In particular, a single axis solar tracking dynamic system is designed, implemented, and experimentally tested to maximally harvest solar energy. In our design, the prototype built is assumed to track sunlight by carrying the panel from eastward to westward thereby tracking the sun from sunrise to sun set and then reset to face eastwards as darkness sets in [7].

\footnotetext{
* Corresponding author, tel: +234-903-938-3320
} 
ANALYSIS AND IMPLEMENTATION OF A SOLAR TRACK ING RACK SYSTEM,

\subsection{Existing Techniques for Capturing Solar Energy}

Mounting of solar panels can be of two (2) main types namely;

(i) Fixed mounted panels, (ii) Tracking mount installations

Fixed mount installation of photovoltaic (PV) usually sees the PV module been affixed at non-alterable angle according to the location in latitude. This system peaks for a short while and then falls back with the sunset. Fixed mounts can be further broken down into;

i., Flush Mounts: The is the most cost-effective option to mount solar panel. Flush mounts are also the simplest to install. A metal bracket is only needed to be attached at both ends of the solar panel so it can be elevated a few inches from the surface, and it is ready for use [8].

ii., Roof/Ground (Universal) Mounts: For a large solar panel system, roof/ground mounts are the best choice. These mounts can be installed using a grid-like system of support on both the ground and on top of roofs hence the name, and most models are adjustable. The advantage of being able to adjust the system is that changing the tilt of the solar panel every three months ensures a more productive system [8].

iii., Pole Mounts: Pole mounts are basically categorized into three, based on how they're positioned on the pole: top of pole mounts, side of pole mounts, and tracking mounts. Top of Pole Mounts is basically a combination of a metal rack and rail unit that is attachded to a sleeve placed on top of a pole. An existing pole 3-8 inches wide is needed prior to installation.. The mount is then slipped over the top of the pole, and the solar panels can be bolted into place [8].

iv., Ground Mount Systems: Ground mounts use a framing system similar in design and orientation to standard passive slanted roof mounting systems, except they are mounted on the ground adjacent to the building or source of consumption. These systems are used when the desired electrical output of the system is limited due to a lack of roof mounting area or simply because of aesthetics [9].

v., Building Integrated Photovoltaics (BIPV): These architecturally pleasing mounting systems occupy a large market for new, innovative design in photovoltaic mounting. These systems can be installed on many building surfaces including vertical walls and atriums similar to glazing systems used in the skylight industry. Wiring is run through interior walls or the support structure with the associated equipment stored in equipment rooms or basements. Some advantages of building integrated mounting systems are:

a., Mounting systems that can be customized to blend into building architecture.

b., Dual benefits of generated solar power and shading, cooling or protection from the elements

c., More esthetically pleasing and versatile than conventional solar mounting systems.

vi., Photovoltaic Solar Canopy, Walkway and

Awning Systems: These mounting systems are unique in that each application has its own architectural design, load and secondary use characteristics. Like building integrated photovoltaics, semi-transparent panels are often used and mounted using a process similar to glazing systems used in skylight construction. The internal wiring is contained within the structural mounting system. In applications where the structure is stand-alone, the balance of the wiring can be run underground or through conduit, while the associated electrical components are housed in the adjacent building.

\section{DESIGN ANALYSIS}

The purpose of a solar tracker is to accurately determine the position of the sun. This enables solar panels interfaced to the tracker to obtain the maximum solar radiation possible. The proposed solar tracker system consist of a closed-loop system which is made up of two main parts which are the electrical system and the mechanical system, incorporated into each other. The electrical system consists of three light detecting resistors (LDR's) which provide feedback to a microcontroller. The microcontroller processes the sensor input and provides output to two H-Bridges. The entire electrical system is powered by a $12 \mathrm{~V}$ direct current (DC) source. The $\mathrm{H}$-bridge controls the DC motor, which are also part of the mechanical system. The mechanical system also consists of gears and bearings which move and positions the photovoltaic array. For diagrammatic simplicity, figure 1 shows the basic block diagram of the proposed system.

The solar tracking rack system comprises of two major segments which can be classified as: (1) Mechanical system; (2) Electrical system

The mechanical system consists of the following:

(a) A metal frame work. (b) Bearings. (c) Two sprocket gears, while the electrical system comprises of the following: 


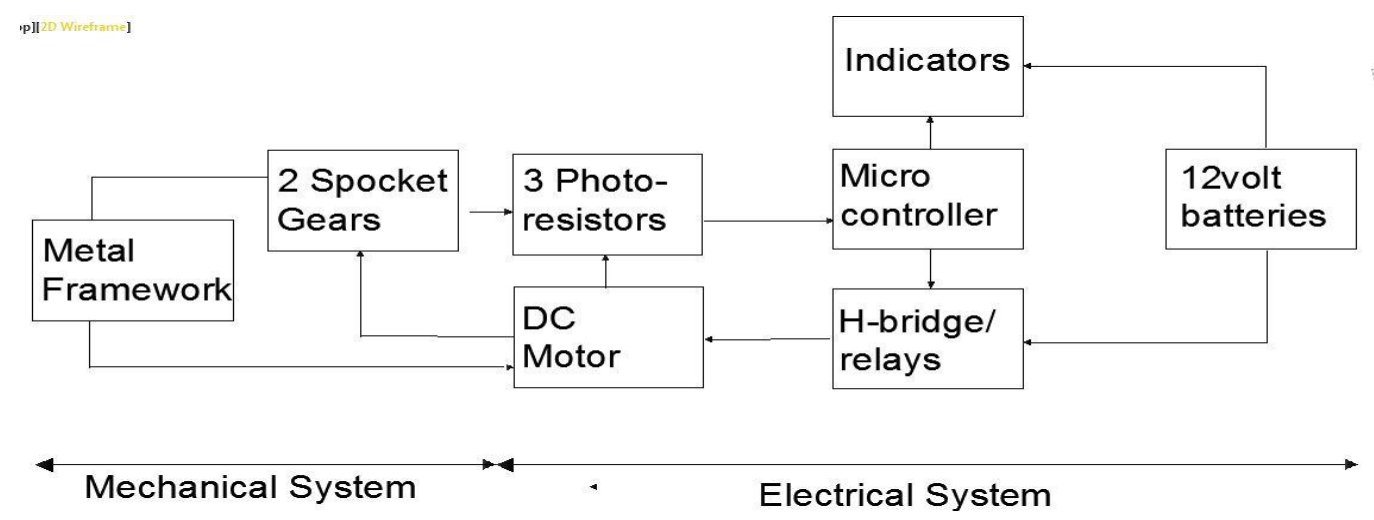

Fig. 1: Simplistic block diagram of the proposed system

(a) Photo voltaic cell with controller; (b) An electric motor (DC motor); (c) The power supply and motor control section; (d) Solar Sensors in Array; (e) Analog Comparator Circuit; (f) Indicators.

\subsection{Mechanical System}

As shown in figure 1, the mechanical system is made up entirely of a metal framework. The metal frame work has incorporated bearings by the side and gears connected to the bearings, and a DC motor which helps in the movement of the metal framework by the electrical system through the help of the gears and bearings.

\subsubsection{Metal frame work}

A galvanized iron rod is placed on a flat plate which is meant to be the base of the entire system. The iron rod is placed vertically on the metal plate. A horizontal member (iron rod) is then placed on the vertical member which is thereafter welded to its flanges at both ends of the rod which is connected with a bolt and knot to a flange extension. The extension is welded to the frame which carries the photovoltaic cell arrays. The metal framework using Autocad design is shown in figure 2 below.

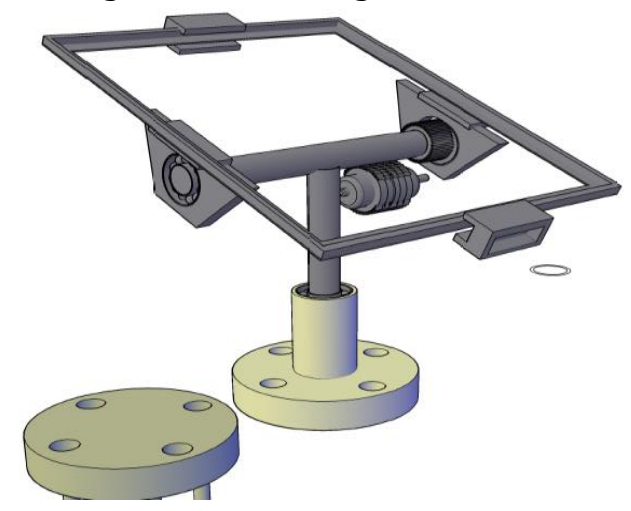

Fig. 2: Conceptual metal framework autocad design

\subsubsection{Ball Bearings}

A bearing is a machine element that constrains relative motion and reduces friction between moving parts to only the desired motion. The bearing is added to the system in order to reduce the friction between the panel hold and the horizontal member during movement.

\subsubsection{Two sprocket Gears}

A gear is a rotating machine part having a cut teeth, which mesh with another toothed part to transmit torque, in most cases with teeth on the one gear being of identical shape on the other gear. Geared devices can change the speed, torque, and direction of a power source. The most common situation is for a gear to mesh with another gear; however, a gear can also mesh with a non-rotating toothed part, called a rack, thereby producing translation instead of rotation motion which is the case with the proposed solar tracking rack. The gear is used as a speed reduction mechanism.

\subsection{Electrical System}

To produce a useful solar tracker, the following is important; the electrical system must give accurate control signal to the mechanical system, it must be reliable, and must have low power consumption. Since analog systems deal with continuous voltages, this seem ideal for providing smooth and accurate control of the mechanical system. Traditional electrical system consists of solar sensors, a comparator circuit and an $\mathrm{H}$-bridge. To improve the proposed system performance, modifications such as: different solar sensors, different solar sensor arrangements, hysteresis to the comparator, and pulse width modulation (PWM) for more precise motor control are implmented. Also, the analog 
comparator circuit is replaced with a digital microcontroller for improved efficiency.

\subsubsection{Photovoltaic Cell with Controller}

Solar cell is a device which converts photons in Solar rays to direct-current and voltage. The associated technology is called Solar Photovoltaic (SPV). A typical silicon PV cell is a thin wafer consisting of a very thin layer of phosphorous-doped ( $\mathrm{N}$-type) silicon on top of a thicker layer of boron-doped (P-type) silicon. An electrical field is created near the top surface of the cell where these two materials are in contact (the P-N junction) [9]. In general, when sunlight hits the semiconductor surface, an electron springs up and is attracted towards the P-type semiconductor material. This will cause more negatives in the n-type and more positives in the Ptype semiconductors, generating a higher flow of electricity. This is known as Photovoltaic effect. The amount of current generated by a PV cell depends on its efficiency, its size (surface area) and the intensity of sunlight striking the surface. For example, under peak sunlight conditions a typical commercial PV cell with a surface area of about 25 square inches will produce about 2 watts peak power.

\subsubsection{Motor}

The purchase of a single $12 \mathrm{~V} \mathrm{DC}$ motor is considered for the proposed system. Unfortunately, the motor had no known part number or documentation. These motors come in different shapes and sizes and have an output from 2,000RPM to more than 16,000RPM, they operate on less than $1 \mathrm{v}$ to more than $24 \mathrm{v}$, and the current required can be less than $100 \mathrm{~mA}$ to more than 5 amps. Some features of these motors are similar and are highlighted below:

1. Motors have a permanent magnet called the FIELD MAGNET.

2. They rotate in the opposite direction when the supply is reversed.

3. They take a high current when starting and a lower current when rotating (spinning) at maximum RPS (Revolutions per Second).

4. They take a higher current when loaded (the motor is driving a load). A load may be placing your fingers on the output shaft or driving through a gearbox and lifting a load or driving wheels via a gearbox.

The torque (twisting ability of the output shaft) depends on the voltage and current as well as the strength of the field magnet and the quality of construction (the closeness of the field magnet to the armature).

a) To drive a motor forward and reverse, the circuit must deliver a voltage in one direction, then in the opposite direction.

b) It must also be able to deliver a "running current" (operating current) (say up to $1 \mathrm{amp}$ ) and a "starting current" (up to $5 \mathrm{amps),} \mathrm{and} \mathrm{a} \mathrm{"loaded}$ current" (up to 5 amps). The transistors must be capable of passing a "stalled current" without being destroyed.

c) The power supply must be capable of delivering a high current so the motor will START-UP under load.

Appropraite test is required to determine the resistance (R), inductance (L), and back electromotive force (EMF), constant $k$ of the motor. These values are required in order to setup an accurate simulation according to the equations for a DC motor. The equation for the voltage across the motor is given as:

$$
V=R i+\partial i / \partial t L+k \omega
$$

The mechanical equation for torque produced by the motor consists of constants for the inertia J, and damping factor $\mathrm{D}$ and the opposing torque $\mathrm{T}_{0}$ :

$$
T=k i=D \omega+\partial i / \partial t J+T O
$$

Measuring for these values would allow an accurate simulation for the motor to calculate power requirements.

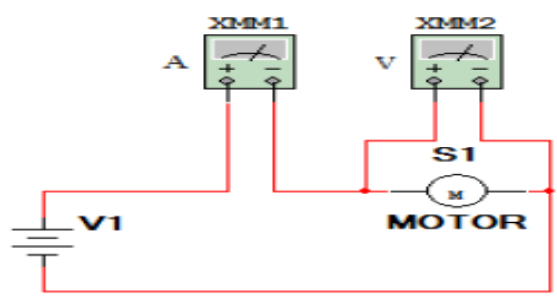

Fig. 3: DC Motor Resistance Test Circuit

From Figure 3, to get a value for the resistance of the motor, voltage and current is measured while the motor is not spinning and the position of the shaft is altered. The resistance could be calculated using Ohm's Law, V = IR. The circuit used has two multimeter, an ammeter and a voltmeter, with the motor connected through the ammeter straight to a variable DC power supply. Because the motor has several poles where the shaft would try to settle in to, the shaft is moved slightly for each measurement so that an average value could be found.

Table 1 shows the result of these measurements. From Table 1, the average current and voltage are 
ANALYSIS AND IMPLEMENTATION OF A SOLAR TRACK ING RACK SYSTEM,

$101.325 \mathrm{~mA}$ and $0.216 \mathrm{~V}$, respectively, and the average resistance is $2.189 \Omega$. This value is rounded to $2.19 \Omega$ for all subsequent calculations.

Table 1: Motor VI Characteristics to Find Resistance

\begin{tabular}{cccc}
\hline Position & Current $(\mathrm{mA})$ & Voltage $(\mathrm{V})$ & Resistance $(\Omega)$ \\
\hline 1 & 78.3 & 0.25 & 3.1928 \\
2 & 117.2 & 0.193 & 1.6468 \\
3 & 107.2 & 0.207 & 1.9310 \\
4 & 97.4 & 0.222 & 2.2793 \\
5 & 100.5 & 0.216 & 2.1493 \\
6 & 108.7 & 0.204 & 1.8767 \\
7 & 113.1 & 0.200 & 1.7683 \\
8 & 88.2 & 0.235 & 2.6644 \\
\hline Average & 101.325 & 0.216 & 2.189 \\
\hline
\end{tabular}

\subsubsection{Power Supply and Motor Control}

In this design, we assume that a rechargeable battery is incorporated to power the tracking system. This is because the solar panel mounted on the tracker is capable of recharging the battery thus making the system self sufficient. Alternatively, to reduce the load on the mounted solar panel, this design incorporates an external charger input to allow charging of the system independently. Taking into consideration that the tracker would be operating in a remote location and the rechargeable battery would have to be replaced eventually, we employ the use of a $12 \mathrm{~V}$ battery. However, in lieu of time and budget restrictions, the battery charging system was not incorporated in the final tracker prototype but the internal charging input was incorporated to allow a user apply an external charger to recharge the system, and $13 \mathrm{~V}$ is kept as the power supply voltage. The DC motor selected can rotate in both directions by reversing the direction of the current supplied. Because the supply on the tracking system has only one pole, we employ the use a $\mathrm{H}$-bridge circuit to efficiently switch the direction of the current to the motor.

From figure 4, two pairs of MOSFET work in conjunction with each other to provide a current through the motor in a certain direction. The upper MOSFETs are P-channel devices while the lower devices are $\mathrm{N}$-channel. Using P-channel devices negates the need to use a voltage doubler to get the gate voltage high enough to turn the device on. When one P-channel MOSFET (Q1) allows current to pass through, and the N-channel MOSFET diagonally across from it (Q4) also allows the passage of current, the motor spins in one direction. If these are both turned "off", and the other two MOSFETs turned "on" (Q2, Q3), the motor spins in the opposite direction. For the H-bridge, the transistors chosen are both power efficient fit with MOSFETs and chosen for their high power efficiency compared to other transistor technologies like the Bipolar Junction Transistor (BJT) which actively draws current in addition to the current flowing through the device. Within the range of MOSFETs, there are also power MOSFETs with a different internal construction that give them high current and/or high voltage capabilities. These power MOSFETs generally have a much lower on-resistance than standard MOSFETs, and therefore have a lower power dissipation and higher efficiency. To further improve power efficiency, a complementary pair is chosen. Complementary transistor pairs are two devices, in this case, one $\mathrm{N}$-channel and one $\mathrm{P}$ channel MOSFET, that are made in a way so that they operate as near identical opposites of each other. For this design, the MOSFETs are acting as switches, the pair switches at the same speed. Based on previous experience, this quality is especially important to prevent the shorting of the $\mathrm{H}$-bridge. If the $\mathrm{P}$ and $\mathrm{N}$ channel MOSFETs on one side of bridge switch at different speeds, one MOSFET can stay on for too long of a time and when the other MOSFET turns on, the H-bridge can short and burn out one of the transistors. A complementary pair negates this by ensuring that there is always some amount of resistance between the two power rails during switching.

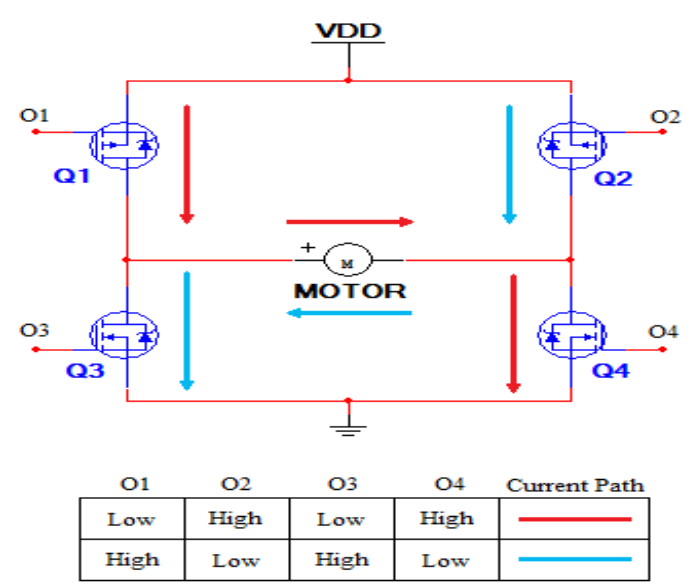

Fig. 4: Basic H-bridge Circuit with SPDT [bottom] and MOSFET [top]

Furthermore, another major consideration in choosing the MOSFETs is the power consideration. The internal on-resistance of the MOSFET determines how much power is dissipated as heat when current 
is flowing through the device. For maximum power efficiency, the amount of power dissipated has to be minimal and therefore the resistance has to be minimal. Additionally, this dissipated power can damage the MOSFET if the device is not properly cooled. For cost purposes, both heat sinks and active cooling systems were avoided and MOSFETs chosen had a low enough power dissipation such that they did not require additional cooling measures. Accordingly, the thermal resistance of the devices has to be taken into account. The thermal resistance is a measure of how many degrees in temperature the device will rise in relation to the ambient temperature when dissipating a certain amount of power, measured in Watts. Because there will be no heat sinks on the $\mathrm{H}$-bridge, the total thermal resistance will be from the device junction to the air. This measure is often included in device datasheets as $R_{\text {өлA. The }}$ lower this measurement, the more power can be dissipated without additional cooling. To calculate the maximum allowable thermal resistance, $R \theta \max$ is gven as:

$$
\Delta \mathrm{T} / \mathrm{P}=\mathrm{R} \theta \mathrm{max} \text {. }
$$

Where $\mathrm{P}$ is the power dissipated by the device, and $\Delta T$ is the difference between the ambient temperature and the maximum operating temperature of the device. Knowing that the tracker will be operating near the equator where high temperatures have been recorded; the ambient temperature in the worst case scenario can take the value of $50^{\circ} \mathrm{C}$. Also, assuming the MOSFET has a typically low maximum operating temperature of $125^{\circ} \mathrm{C}$, then $\Delta \mathrm{T}$ under the worst-case condition is $75^{\circ} \mathrm{C}$. The power dissipated by the device can be calculated as the product of the internal resistance and the current squared:

$$
P=I^{2} R \text {. }
$$

Knowing that the maximum current drawn by the motor during testing is $\approx 1500 \mathrm{~mA}$, the equation to calculate the maximum thermal resistance now becomes:

$$
25^{\circ} \mathrm{C} /(0.160 \times R O N)=R \theta \max
$$

Power MOSFETs typically come in a non-insulated To220 package which has a typical thermal resistance junction-to-air of $\approx 65^{\circ} \mathrm{C} / \mathrm{W}$. Therefore $\mathrm{R} \theta_{\max }>$ $65^{\circ} \mathrm{C} / \mathrm{W}$. Plugging this inequality into equation (5) and solving for Ron, the minimum on-resistance can be calculated as:

$$
R O N<2.404 \Omega
$$

This calculation is the maximum rating that the power MOSFETs used in the $\mathrm{H}$-bridge can have assuming their maximum operating temperature is $125^{\circ} \mathrm{C}$, and the thermal resistance junction-to-air is $65^{\circ}$. Taking these specifications into consideration and keeping in mind that any component chosen has to be available across the world to reduce repair costs, the power MOSFETs chosen is the complementary pair of IRF530 N-channel MOSFETs and IRF9530 P-channel MOSFETs as shown in Figure 5. Figure 6 shows the schematic for the final $\mathrm{H}$-bridge circuit block. The diodes connected across the drain and source terminals of the MOSFETs are for the inductive kickback from the motor. This kickback is a high voltage spike which can easily damage the MOSFETs. The diodes are chosen such that if the voltage gets above a certain value, they effectively short the motor to the rails and the spike is eliminated.

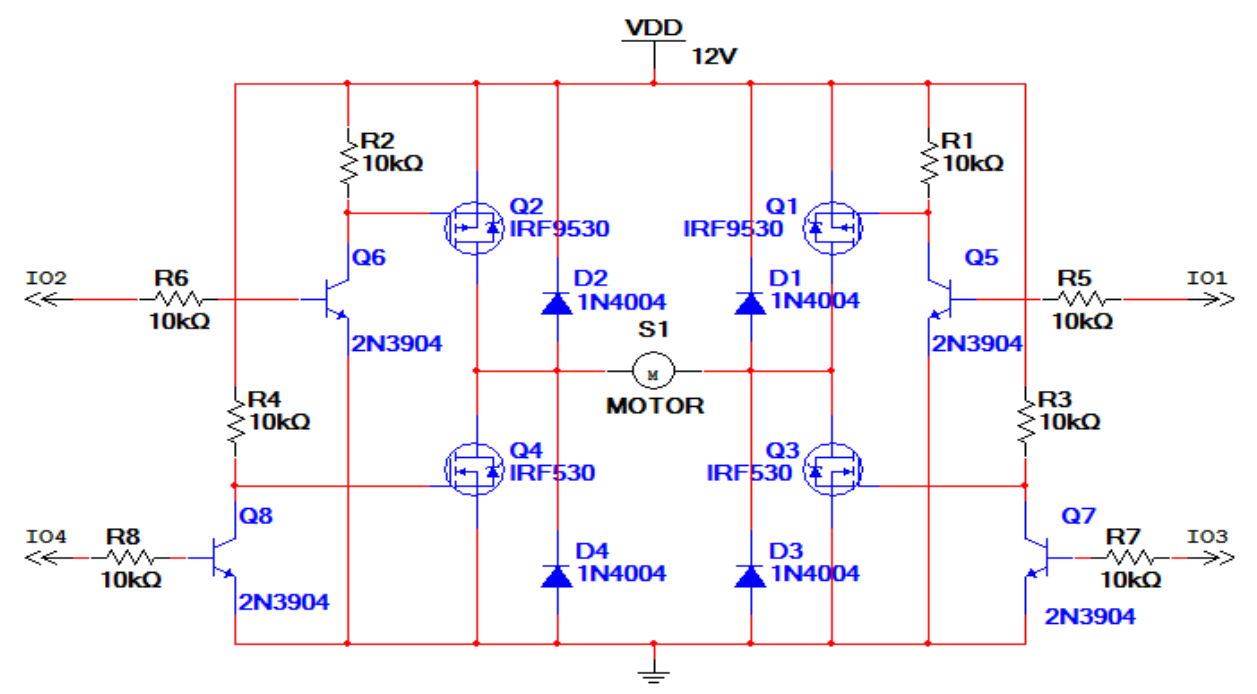

Fig. 5: Revised H-bridge Schematic 


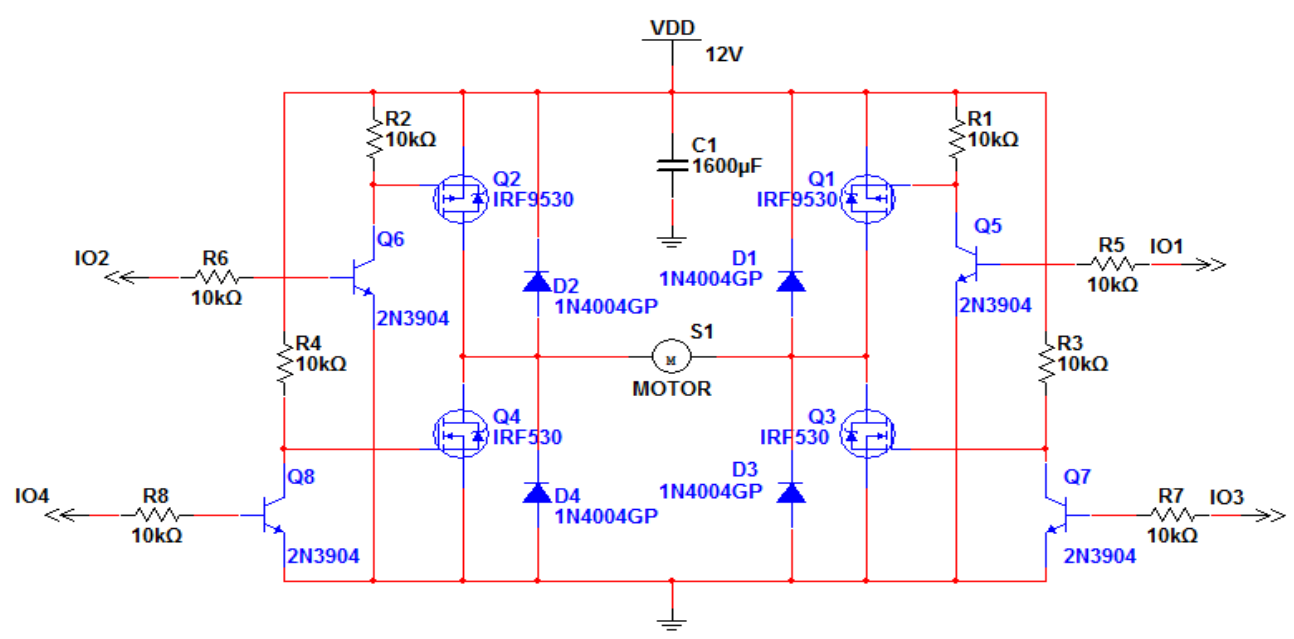

Fig. 6: Final H-bridge circuit

The $1 \mathrm{~N} 4004$ rectifier diode is ideal for this application because of its high surge current capability and wide availability.

Since the motor will be moving for a very small percentage of the day, the power used when the $\mathrm{H}$ bridge is "off" or not supplying any power to the motor needs to be minimal. The resistors in the circuit were chosen such that when the $\mathrm{H}$-bridge is off, the current drawn is $<5 \mathrm{~mA}$ for efficiency. Testing the circuit with the motor parameters in Multisim show that the total current drawn when the H-bridge is "off" is $4.65 \mathrm{~mA}$ which is $55.8 \mathrm{~mW}$. Higher value of resistors would lower the current drawn but would also increase the switching time of all the MOSFETs which would increase the transient current drawn.

During testing, many of the mechanical systems did not move slowly enough given the $\mathrm{H}$-bridge, and in turn, the motor is directly supplied by the full power rail voltage. To combat this, reducing the speed of the motor would circumvent the need to make any severe mechanical changes to the system. However, the easiest way to lower the speed of the motor is by adding a resistor in series with the motor. This method lowers the torque of the motor and reduces its ability to effectively turn the system. Using a PWM signal, however, can lower the speed of the motor without having a significant impact on the torque. When using the analog comparator circuit outlined in Figure 10, the PWM signal need to come from an external source because the comparator is unable to provide this signal. For this, a 555 Timer is used to create a PWM signal which is then connected to the collectors of Q7 and Q8, through their respective resistors R3 and R4, in the $\mathrm{H}$-bridge circuit above. This system proved to be an effective way to significantly reduce the speed of the motor which allows the tracker more precise movement. Using PWM to control the motor necessitates a power capacitor to handle the surge currents of the motor. When the motor is switching on and off as well as reacting to changes in its mechanical load, the current drawn can change quickly and will drop the voltage delivered by the power supply. The frequency of the PWM used in the final circuit, supplied by the microcontroller, is $300 \mathrm{~Hz}$ according to the datasheet. The maximum load current is $400 \mathrm{~mA}$ from the maximum measured current going to the motor during testing. This capacitor is added between the $12 \mathrm{~V}$ power rail and ground for both $\mathrm{H}$-bridges used.

\subsubsection{Solar Sensors in Array}

To provide an accurate and reliable tracking of the sun, a solar sensor array was designed as shown in Figure 7. Based on previous works [10], photoresistor as shown in Figure 7 are considered as possible sensors. The solar sensors are primarily chosen based on the linearity of the output response due to the change in the angle of incidence.

The sensor tilt angle that obtained the highest angular response is chosen. For this design, two photoresistors were used, each with a measured dark resistance of $1.36 \mathrm{M} \Omega$. These sensors were both mounted perpendicular to the light source.

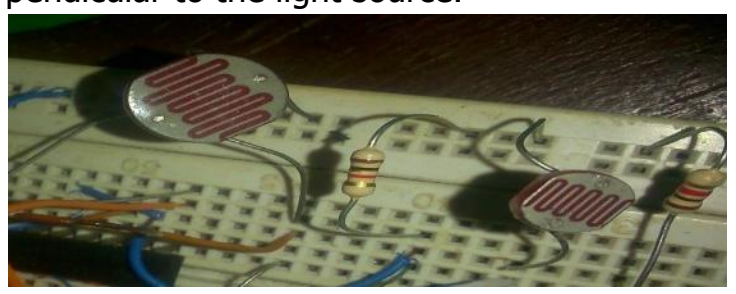

Fig. 7: Perpendicular Photoresistors 


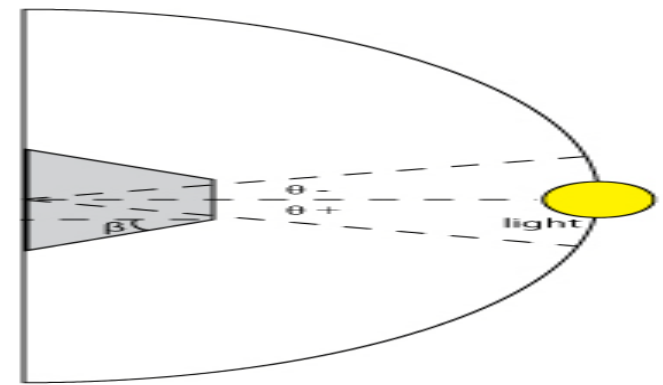

Fig. 8: Setup to Test for Ideal Tilt Angle

In order to determine a tilt angle that provided the best accuracy, and the best response to a change in the angle of incidence, a test setup with a torchlight is investigated. The adjustable mount allowed for tilt angles of $25^{\circ}, 35^{\circ}, 45^{\circ}, 55^{\circ}$, and $65^{\circ}$. The light is positioned approximately a foot from the adjustable tilt mount. A separator fixed by the mount allowed the light to be rotated around the mount, while maintaining the foot long distance. This setup is seen in Figure 8. Figure 8 represent the angle of incidence as $\theta$, and the tilt angle as $\beta$. For testing, the photoresistors are each setup in a voltage divider with a $1 \mathrm{~V}$ source and a $5 \mathrm{k} \Omega$ resistor, as shown in figure 9. The angle of incidence from the bulb is varied by $5^{\circ}$ from $-90^{\circ}$ to $90^{\circ}$, and the voltage

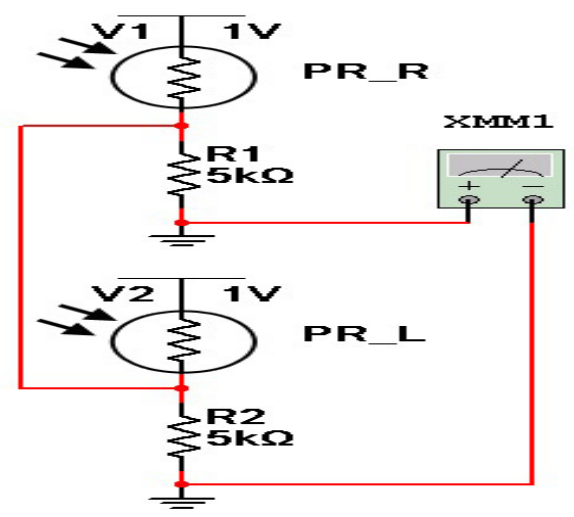

Fig. 9: Photoresistor Voltage Divider Circuit difference between the two photoresistor voltage dividers is measured and recorded. This is done for all five tilt angles. It was observed that higher tilt angles are not desirable, since there is only a slight voltage difference at lower angles of incidence.

\subsubsection{Analog Comparator Circuit}

To provide an interface from the solar sensors to the $\mathrm{H}$-bridge, a circuit that compares the voltage of two photoresistors, and outputs a control signal to each of the four MOSFET inputs of the H-bridge is designed. This circuit design is needed to accurately sense the voltage difference between the photosensors, and provide reliable inputs to the $\mathrm{H}$-bridge. The first section of this circuit that detects the voltage difference is composed of an analog comparator circuit. The second section that provides the control inputs to the $\mathrm{H}$-bridge consists of logic gates. Note that the two photoresistors are used as photosensors. To obtain a voltage that depends on the change in resistance of the photoresistor, a voltage divider is designed. For convenience, the voltage divider is powered by $5 \mathrm{~V}$ supply. A $50 \mathrm{k} \Omega$ potentiometer is used to complete the voltage divider. This potentiometer is used for calibration, since the photoresistors are not exactly matched and the value is chosen to reduce current through the circuit. At the output, a $50 \mathrm{k} \Omega$ resistor is used as current protection. The LM741 is a common operational amplifier with a power dissipation of $500 \mathrm{~mW}$. Two LM741 are connected to the two sensor voltage dividers and configured in the nofeedback comparator setup. This comparator setup has an overall power dissipation of $1 \mathrm{~W}$. The output from the comparator circuit are not necessarily discrete, thus an N-channel MOSFET is used. The ZNN2110A N-channel MOSFET is chosen since it is readily available and has a power dissipation of 700 $\mathrm{mW}$. Since two units are used for each comparator, there is an overall power dissipation of $1.4 \mathrm{~W}$. Finally, two red LEDs are used to indicate the photosensor with the highest light intensity. When the light intensity is greater on one photoresistor, the respective LED would turn on, while the other LED turns off. When the light radiation is equal on both photoresistors, both LEDs turned on. A red LED is used since it requires approximately $1.6 \mathrm{~V}$, which is the lowest voltage required compared to other colored LEDs. The red LED requires about $20 \mathrm{~mA}$ of current and thus, the closest resistor of $200 \Omega$ to the following calculations was chosen.

$$
R=\frac{5 V-1.6 V}{20 m A}=170 \Omega
$$

For this research work, modifications are made on the comparator circuit. In particular, the two LM741 Opamps are replaced with a single LM324 quad Op-amp. This is done to reduce the space usage, and the LM324 has a lower power dissipation of $400 \mathrm{~mW}$. In addition, the inverting inputs are set to an adjustable voltage source. This is because to put the system at rest, the voltages from both photoresistors have to be exactly identical. Without any space to keep the system at rest, the comparator never reached a steady state during testing with a stationary light source. A third change is the use of photovoltaic cells instead of the 
photoresistor voltage divider setup. Finally, the power supply was changed to a $12 \mathrm{~V}$ source, the schematic for this combined circuit is shown in Figure 10.

As mentioned earlier, the $\mathrm{H}$-bridge requires accurate control inputs to each of the four MOSFETs. However, the constructed comparator in figure 10 only provides two inputs, thus, a set of logic gates is used to obtain the required four inputs. When the comparator outputs two high signals, which corresponds to the tracker being pointed at the light source, outputs to the P-channel MOSFETs on the bridge need to go low, and the outputs to the N-channel MOSFETs need to go high. If one sensor shows a higher light intensity, the corresponding output goes high. The logic circuit needs to send a signal to the $\mathrm{H}$-bridge to turn on the P-channel and N-channel MOSFETs that correspond to the rotation of the system in the direction of the light. The reverse goes for the opposite sensor. Finally, when both sensors output a low value, which is impossible, but still needs to be planned for, the $\mathrm{H}$ bridge needed to be shut off in the same fashion as when the sensors outputs are both high. The truth table for the logic gate is shown in Table 2. Outputs 1 and 2 correspond to the P-channel input, and outputs 3 and 4 go to the $\mathrm{N}$-channel inputs. Outputs 1 and 3 go to the same side of the $\mathrm{H}$-bridge, and 2 and 4 go to the other side.

\subsection{Digital System}

As a result of the drawbacks present in the analog control system, a microcontroller-based digital control system is also considered. In general, the microcontroller allows a minimal control circuit complexity, reduced power consumption and allows for additional features to be introduced to the tracker. The microcontroller selected has at least four analogto-digital converter (ADC) inputs to take the two signals from the two sensors. It also has a minimum of four digital outputs for the motor H-bridges.

Finally, the microcontroller employed in this design has a very low power consumption when active, to keep the efficiency as high as possible. The most widely available microcontrollers that satisfy these requirements are either AVR or PIC microcontrollers. For this design, the version used is the ATmega 328P microcontroller, and PIC16F876A which has six and five $A D C$ inputs, respectively, and 14 digital output pins, six of which can support a PWM output. The board also has an on-board power regulator which can take the $12 \mathrm{~V}$ power supply directly to supply the $5 \mathrm{~V}$ required by microcontroller.

Table 2: Comparator truth table

\begin{tabular}{cccccc}
\hline $\begin{array}{c}\text { Sensor } \\
\mathrm{L}\end{array}$ & $\begin{array}{c}\text { Sensor } \\
\mathrm{R}\end{array}$ & $\begin{array}{c}\text { Output } \\
1\end{array}$ & $\begin{array}{c}\text { Output } \\
2\end{array}$ & $\begin{array}{c}\text { Output } \\
3\end{array}$ & $\begin{array}{c}\text { Output } \\
4\end{array}$ \\
\hline 0 & 0 & 0 & 0 & 1 & 1 \\
0 & 1 & 1 & 0 & 0 & 1 \\
1 & 0 & 0 & 1 & 1 & 0 \\
1 & 1 & 0 & 0 & 1 & 1 \\
\hline
\end{tabular}

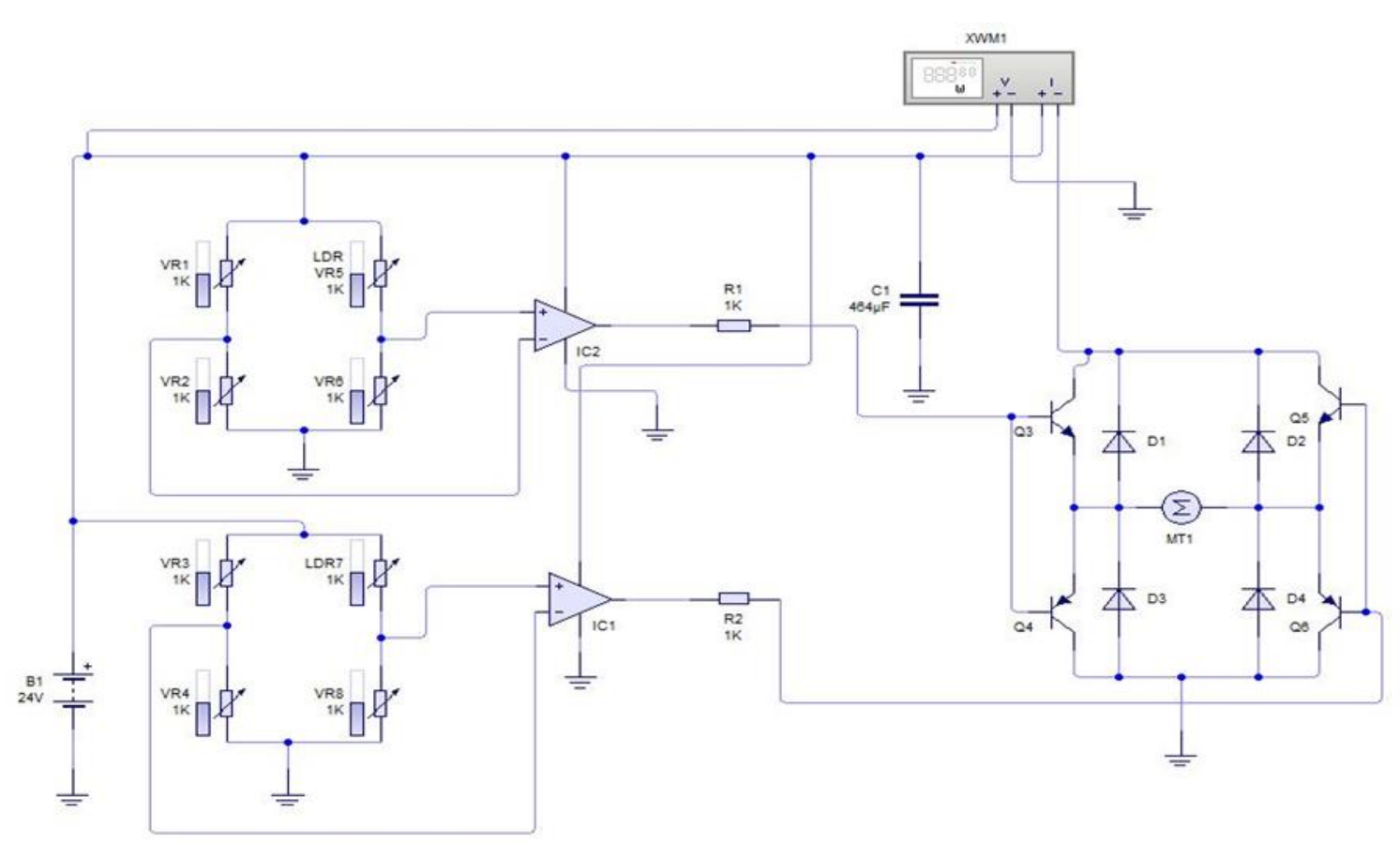

Fig. 10: Analog comparator circuit 
The PWM outputs of the microcontroller in particular, allow the removal of the external PWM generator used in the analog system for a more power efficient and centralized controller. In the future, this development board can be replaced with just a microcontroller with similar inputs and outputs but lower power consumption, and without the extraneous circuitry provided on the board.

The function of the microcontroller is to compare the voltage levels of the two sensors for one axis of rotation, and send the appropriate signal to the $\mathrm{H}$ bridge to move the motor in a certain direction. To reduce the amount of jitter the system has, the microcontroller takes the two voltage values of the sensors and finds the difference between the two. The difference is compared to some reference value. If it is greater than the positive reference value, the microcontroller sends a signal to the $\mathrm{H}$-bridge to move the tracker in one direction. If the difference is less than the negative reference, the microcontroller sends a signal to move the tracker in the opposite direction. Setting the reference to zero will reduce the error to the minimum but it will also introduce significant jitter when a shadow passes over the sensors. Setting the reference to a value greater than zero allows some hysteresis into the tracker but also increases the error. Additionally, the microcontroller examines the voltage outputs of the sensors in relation to night-time conditions. If the values correspond to those during night-time, the tracker will shut everything off except for the microcontroller to decrease power consumption. This also avoids the problem of the tracker focusing on a nearby night-time light source such as a streetlamp or building. The mechanical components consisted of the DC motors, the sprocket gears and the PV sensor array each described above.
Electrically, the tracker will most likely use PICIF16F876A microcontroller, the H-bridge circuit and 12 volt rechargeable batteries to supply the power. Secondly, the speed of the motor has to be calculated by putting the motor under load, and changing the PWM amounts to obtain the slowest effective speed to drive the tracker. Effectively, work done in [7] clearly enumarates how the speed of such motor for similar design can be calculated. The calculation is however not considered in this work.

\section{$2.4 \quad$ Final System}

An overall system simulation and a final prototype for the tracker is created. The mechanical components consist of the metal frame work, DC motors, the worm gears, and the solar panel sensor array each described above. Electrically, the tracker uses the microcontroller, the $\mathrm{H}$-bridge circuit, and the rechargeable batteries to supply the power to the system. Also, a PWM circuit was added to the system using a 555 timer and other components so as to reduce the speed of the $D C$ motor for stable tracking of the solar system.

\subsubsection{Total system simulation}

To understand how the tracking system operates before construction; an ideal simulation is created for the system rotation. LIVEWIRE system simulator is chosen as the medium for the simulation because it could more accurately simulate the processes of the transistors than PSPICE or MULTISIM. The first part of the simulation involves the collection of system specifications. The major portion of the simulation rely on an accurate representation of how the sensors operate during the day.

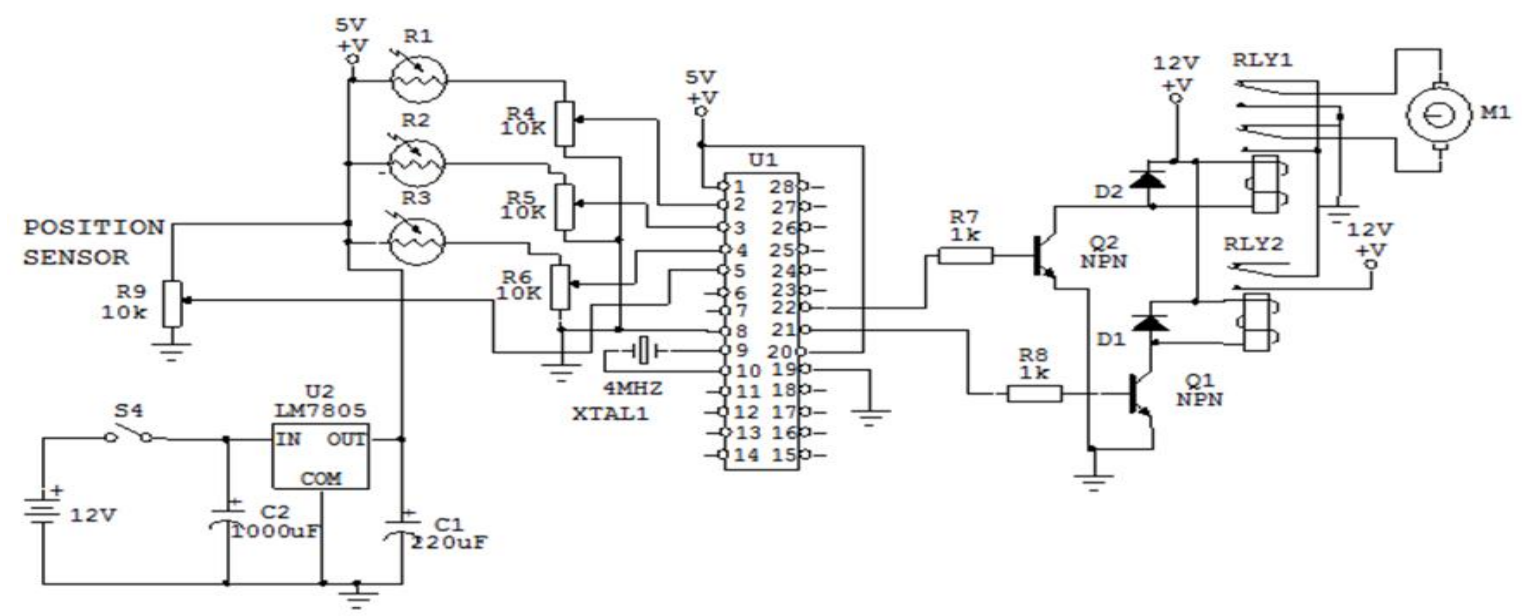

Fig. 11: PIC digital schematic 


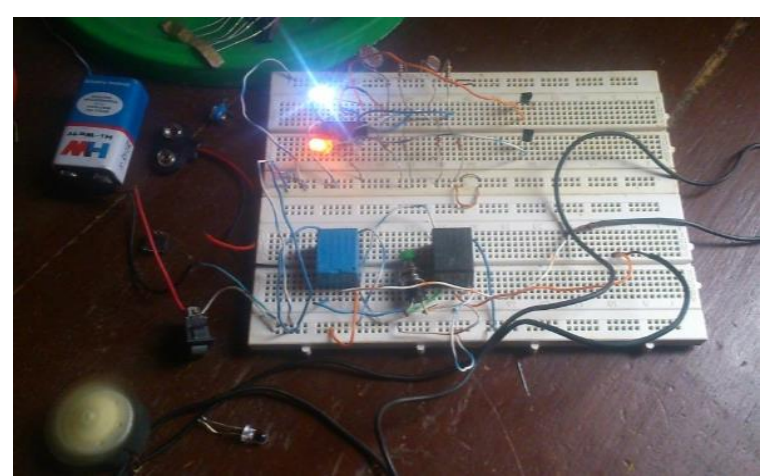

Fig. 12: Completed system breadboard prototype testing

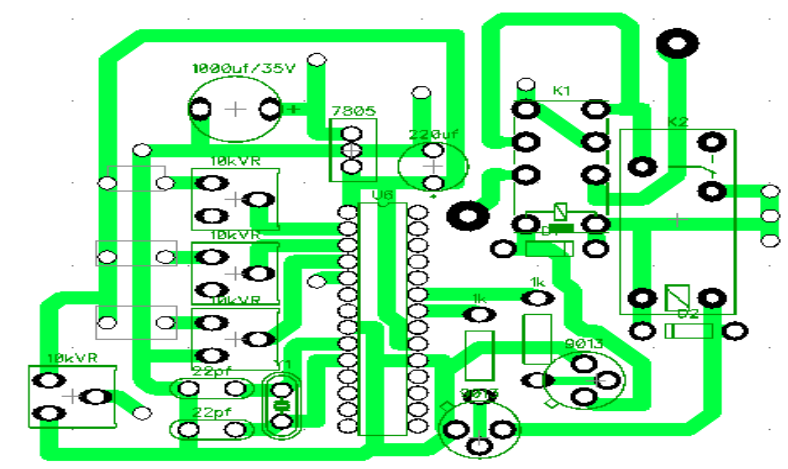

Fig. 13: PCB Layout

\subsubsection{Construction}

The final system design consist of a mechanical assembly made of opaque electrical containment boxes to demonstrate the inner workings of the system. Also, the final system consist of aluminum, steel, and brass parts for the axle, spindle and motor mount assemblies, and the electrical control system which is composed of the microcontroller development board, and two custom-made printed circuit boards (PCBs) for the $\mathrm{H}$-bridge and other circuitry like the PWM motor control. Because of the rechargeable battery implementation, power to the tracker is supplied by $12,7.2 \mathrm{AH}$ lead-acid batteries to get the necessary $12 \mathrm{~V}$, and controlled with a single-pole, single-throw (SPST) power switch. A charge input and control circuit is also implemented to allow independent charging of the battery as desired by the operator.

\subsubsection{The PCB}

The PCB as shown in figure 13 is designed to incorporate the circuitry in the smallest footprint possible. The circuits it holds are the $\mathrm{H}$-bridge for the motor, the potentiometers for balancing the signals from the solar panels, and two indicator LEDs used for troubleshooting the system. Because of the requirements of one axis of the track, the $\mathrm{PCB}$ is designed for one axis. This allows a more compact board size.

\section{SYSTEM ANALYSIS, TEST AND CONSTRUCTION}

Once the altitude single axis solar tracker is built, test for the angular error, and the power consumption was conducted.

\subsection{Functionality Testing Results}

The prototype was put through several tests of functionality to ensure that it met the original design requirements. The tracker's angular error and power consumption were measured to calculate the tracker's power generation in comparison to other solar panel systems.

\subsubsection{Angular Error}

The first test of the prototype is to measure the angular difference between a light source and the tracker center, referred to as the angular error. To do this, the altitude axis of the tracker is disabled by removing power to the $\mathrm{H}$-bridge. The altitude axis is also oriented at $90^{\circ}$ so that the azimuth sensors is perpendicular with the light source. Then, the exact center of the tracker is found and marked by measuring to the exact center of the sensor array, and translating that center to the bottom platter using a pendulum. The test setup comprises of a high intensity flash light at the same height as the sensors, and kept at 45 inches away from the tracker using a wooden beam. The beam was notched at one end so it could rotate around the same axis as the tracker.

A large protractor is needed to measure the degree difference. For this test, the tracker center was oriented at a starting point and shut off. The light is set to the $0^{\circ}$ mark on the protractor so that the error before turning the tracker on is at its starting position in degrees. Then, the tracker is turned on and its movement to find the light was closely observed. Notable features in the movement consist of whether or not the tracker "overshot" the light or moved past the $0^{\circ}$, whether the tracker jittered when it got close to the light and if it even reached a stationary point. If the tracker did reach a stationary point, the angle of difference is recorded and the test repeated for the same starting angle in the opposite direction. The first test was done with a starting point of $45^{\circ}$, the microprocessor reference set at $11.3 \mathrm{v}$ meaning an allowable difference of approximately $700.4 \mathrm{mV}$ between the panels, and the motor PWM amount set 
at 210 which is a speed reduction of $17.65 \%$. When the tracker was set directly in line with the light, the left sensor input to the microcontroller measured at $12 \mathrm{~V}$ and the right sensor measured at $12.2 \mathrm{~V}$. Starting counter clockwise, arbitrarily called the negative direction, from the light at $45^{\circ}$, the tracker hit a steady state with an angular error of $2.5^{\circ}$ short of the light. Starting clockwise, the positive direction, from the light, the tracker hit a steady state with no discernable angular error to the light. Increasing the starting point to $75^{\circ}$ in both directions, the angular error changed to $3^{\circ}$ falling short of the light coming from $+75^{\circ}$. Coming from $-75^{\circ}$, the tracker actually overshot the light by $1^{\circ}$. This error is obviously due to the mismatch between the two solar panel voltages going to the microcontroller.

Adjusting the voltages going to the microcontroller by using the potentiometers on the circuit boards, the left sensor display a voltage of $12.0 \mathrm{~V}$ and the right sensor display a voltage of $12.0 \mathrm{~V}$, effectively equating the voltage between the two sensors. Again, measuring the angular error with the tracker starting at $\pm 75^{\circ}$ to the light, the error was $0.5^{\circ}$ short of the light coming from $-75^{\circ}$. Coming from $+75^{\circ}$, the error was $1.5^{\circ}$ short of the light.

It should be noted that even with the panels not closely matched, the total angular error calculated by adding the error in both directions was right around $2^{\circ}$ which closely correlates with the simulation results of $1^{\circ}$ of error in both directions. To gauge how the tracker would act when the sensors were wrongly calibrated by a large degree, the potentiometers were adjusted so that the left sensor outputs $0.622 \mathrm{~V}$, and the right sensor outputs $0.735 \mathrm{~V}$. Starting from $+75^{\circ}$, the tracker rotated to the right and never reached a steady state. This would be hazardous to the altitude axis where the sensor array does not have the clearance to rotate the full $360^{\circ} .48$ [8]. Narrowing the difference between the sensors so that the left sensor outputs a voltage of $0.744 \mathrm{~V}$, and the right sensor output $0.771 \mathrm{~V}$, the same test was performed. Coming from $+75^{\circ}$, the tracker stopped $9^{\circ}$ short of the light source. Coming from $-75^{\circ}$, the tracker stopped at $5.5^{\circ}$ past the light source. This shows that miscalibration not only increases the angular error in both directions of rotation, it also increases the total angular error of the tracker keeping it only within $4.5^{\circ}$ of the light source.

\subsubsection{Power Consumption}

To ensure that the tracking system produces more power than it consumes, measurement was taken for the power consumption of each individual component of the system. A single $0.49 \Omega$ (measured value) resistor is used as a power shunt to measure the current going from the battery to the tracker system as shown in the circuit in Figure 15.

The voltage measured by the voltmeter VR1 divided by the resistance gives the current to the tracker. Multiplying the current by the supply voltage $12 \mathrm{~V}$, the power consumption can be calculated. Several measurements were taken to find the individual current drawn to each section of the system. The first measurement was to the total system, with the shunt between the battery and the rest of the system. The currents were measured when the system was stationary, one axis was moving, and the other axis was moving, and both axes moving at the same time. To get just one axis to move, the sensor inputs to the microcontroller were 49. Incorrectly biased so that the system saw a difference and tried to correct it. For measuring the voltages when the system was moving, the voltages were taken at the highest observed value. The result is shown in Table 3.

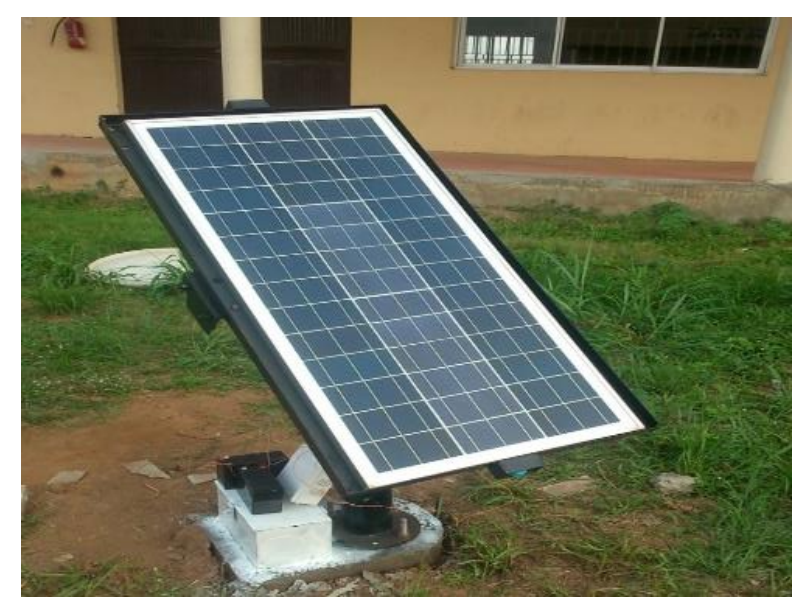

Fig. 14: Solar tracking rack system

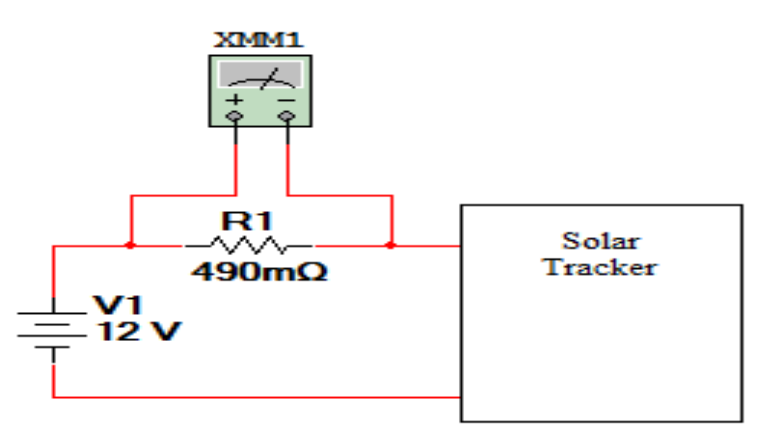

Fig. 15: Power Consumption Test Circuit 
ANALYSIS AND IMPLEMENTATION OF A SOLAR TRACK ING RACK SYSTEM,

Table 3: Total System Power Consumption

\begin{tabular}{llll}
\hline Position & $\begin{array}{l}\text { VR1 } \\
(\mathrm{mV})\end{array}$ & $\begin{array}{l}\text { Current } \\
(\mathrm{mA})\end{array}$ & Power (W) \\
\hline $\begin{array}{l}\text { Stationary } \\
\text { Clock wise moving }\end{array}$ & 19.4 & 39.59 & 0.48 \\
$\begin{array}{l}\text { Anticlockwise } \\
\begin{array}{l}\text { Moving } \\
\text { Both Axes on with }\end{array}\end{array}$ & 110.0 & 260.0 & 1.60 \\
LED & 110.0 & 260.0 & 2.60 \\
\hline
\end{tabular}

From these results, the following can be deduced. The microcontroller, the indicator LED, and the quiescent current to the $\mathrm{H}$-bridges consumes $0.48 \mathrm{~W}$ when the system is stationary. The clockwise axis consumes $1.60-0.48=1.12 \mathrm{~W}$ when moving sensors through the maximum load point, or when the sensors are parallel to the ground. The anticlockwise axis consumes $2.60-0.48=3.12 \mathrm{~W}$ at its maximum load point as determined by the friction in the mechanical part. The total power consumption at the maximum load point is equal to $0.48+1.12+3.12=4.72 \mathrm{~W}$. The difference between this amount and the measured amount is due to the tracker not moving through both maximum load points at the same time which would (from the circuit design) make the device go into a perpetual one directional rotation. These measurements conclusively show that the power consumption when the system is not moving to be just less than half a Watt, and when the system is moving both axes in a worst-case scenario, it consumes $4.72 \mathrm{~W}$.

\subsubsection{Comparison to Other Systems}

The final part of the functionality test of the tracking system is to compare its performance to other types of panel orientations and tracking systems. To do this, an accurate simulation of the sun's angle to a particular point on the earth's surface is needed to calculate the power and energy gained by a tracking system. To simplify the math, a few assumptions were made. Firstly, it is assumed that the earth is perfectly spherical so that elevation of the solar panel setup does not come into play. Secondly, it is also assumed that the sun moves from exactly east to exactly west every day of the year. Thirdly, it is assumed that the year is exactly 365 days, 24 hour per day or 8760 hours per year. Finally, it is assumed that the time at the point of the solar panel corresponds to the sun's position so that at midnight, the sun is exactly behind the earth at $180^{\circ}$ to the zenith, and that at noon, the sun is directly between the east and west horizons or $0^{\circ}$ to the zenith [8].

Given that the earth rotates a full $360^{\circ}$ in 24 hours in an east-to-west direction, the following equation can be given for the angle of the sun to the zenith of the point on the earth given in the east-west direction henceforth called the $X$ direction:

$$
Z X=15^{\circ}(t-12)
$$

The variable $t$ is the amount of time from midnight on the first day of the simulation in hours. This equation gives the following results:

$\mathrm{t}=0$ hours (midnight first day), $\mathrm{ZX}=15^{\circ}(-12)=-$ $180^{\circ}$

$\mathrm{t}=12$ hours (noon first day), $Z X=15^{\circ}(0)=0^{\circ}$

$\mathrm{t}=24$ hours (midnight second day), $Z X=15^{\circ}(12)=$ $180^{\circ}$

$\mathrm{t}=36$ hours (noon second day), $\mathrm{ZX}=15^{\circ}(24)=$ $360^{\circ}=0^{\circ}$, and the cycle repeats daily.

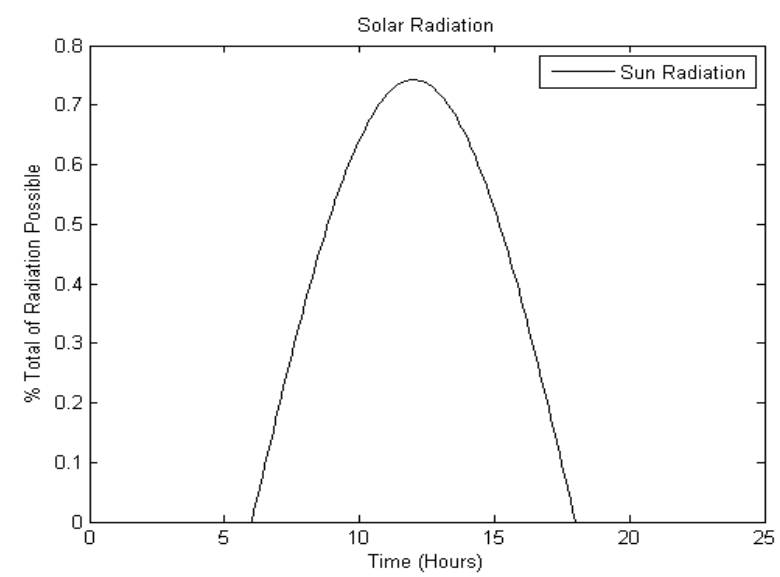

Fig. 16: Percent Total Solar Radiation in the Vernal Equinox

From Figure 16, notice how the percentage gain of the radiation never reaches $100 \%$ again. This is because the sun is off by $42.2625^{\circ}$ from Worcester on the vernal equinox. To ensure that the angle $Z Y$ is changing correctly, the plot time was widened to a full 365 days, 8760 hours per year and Figure 17 was produced. Figure 17 shows the graph of percentage solar radiation in a year.

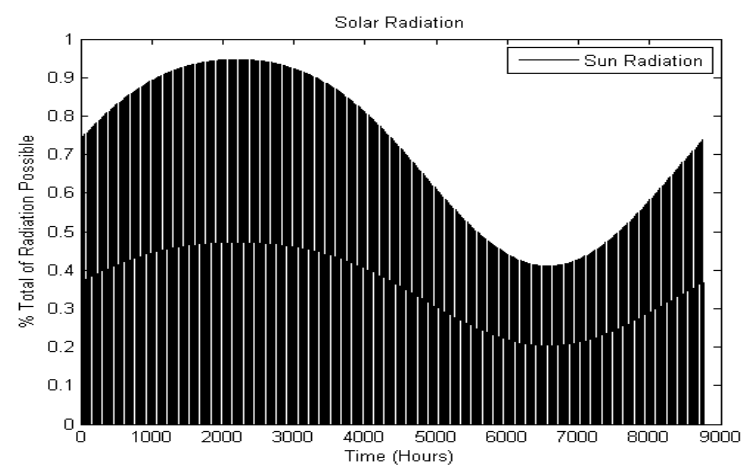

Fig. 17: Percent Total Solar Radiation in a Year 
The solidity of the plot is due to the fact that the radiation is oscillating every day and there are 365 days' worth of data in the above plot. However, it does show that the percentage total varies over the year as well as over the day, and returns to the same point as it began verifying the equation for ZY. Also, the percentage again never reaches $100 \%$ because Worcester has latitude greater than $23.5^{\circ}$ so the sun can never be directly overhead [9]. To calculate the percentage radiation absorbed by the solar tracking system, several observations are made about the movement of the tracker. The first is that the tracker will always follow the sun slightly behind its actual position by a maximum of $1.5^{\circ}$ in both directions as verified by the measurements. Taking the cosine of this angle shows that the tracker will be able to absorb $99.97 \%$ of all available light in one direction. The tracker will always orient any solar panel on it perpendicular to the sun in perfectly clear conditions. Therefore, based on these assumptions, the radiation absorbed by a panel mounted on this tracking system will be $99.93 \%$ of the total radiation. Before plotting the equation for the single tracker system over time, equations for several other systems need to be derived for comparisons [10]. The first being the tracker that only tracks in the east-west or $X$ direction which is also referred to as a Horizontal Single Axis Tracker (HSAT). Firstly, assuming the HSAT uses the same tracking system as the dual axis tracker, the tracking angle will lag slightly behind the sun by $1.5^{\circ}$ over the course of a day. This means in the X direction, HSAT can only absorb $99.97 \%$ of the radiation available. Secondly, assuming HSAT will be oriented in the $Y$ direction so it is pointed towards the zenith. Therefore, HSAT percentage absorbed will also rely on the angle of the sun in the $Y$ direction which it cannot compensate for. Tracking can also be done in the $Y$ direction. This is usually done by using an immobile panel and varying its degree to zenith over the year to keep the sun's angle to the panel minimal without any mechanics. To simplify the mathematics and make the comparisons more relevant, two things are assumed. First, the tracker, man or machine, has the same amount of error in the $Y$ direction as the HSAT tracker has in the $X$ direction which is $99.97 \%$. Secondly, the panel is oriented in the $X$ direction towards the zenith in the same way that the HSAT is oriented in the $Y$ direction. Therefore, the $\mathrm{Y}$ direction tracker percentage absorbed will also rely on the angle of the sun in the $X$ direction which the tracker cannot compensate for.
Table 4: Photovoltaic test data [voltage]-[time]

\begin{tabular}{ccc}
\hline TIME $(\mathrm{HRS})$ & IMMOBILE $(\mathrm{V})$ & TRACKING $(\mathrm{V})$ \\
\hline $6 \mathrm{am}$ & 15.90 & 16.50 \\
$7 \mathrm{am}$ & 17.8 & 17.60 \\
$8 \mathrm{am}$ & 17.9 & 17.90 \\
$9 \mathrm{am}$ & 17.8 & 18.10 \\
$10 \mathrm{am}$ & 18.1 & 17.90 \\
$11 \mathrm{am}$ & 18.1 & 18.10 \\
$12 \mathrm{pm}$ & 17.2 & 18.4 \\
$1 \mathrm{pm}$ & 17.3 & 18.2 \\
2pm & 17.8 & 17.91 \\
$3 \mathrm{pm}$ & 16.43 & 18.1 \\
$4 \mathrm{pm}$ & 15.6 & 17.74 \\
$5 \mathrm{pm}$ & 12.60 & 17.7 \\
$6 \mathrm{pm}$ & 15.6 & 16.9 \\
$7 \mathrm{pm}$ & 12.6 & 15.5 \\
\hline
\end{tabular}

The final panel orientation to be compared is the immobile panel orientation. This is achieved assuming that the panel is placed perfectly levelled with the ground so that the panel's normal is perfectly oriented to the zenith. The percentage of radiation absorbed with an immobile panel will be a function of the angle of the sun in both directions. However, the tracking system uses a certain amount of power over the entire year to track the sun at that degree of precision. Based on the measurements in Table 4, the tracker consumes $2.60 \mathrm{~W}$ during movement. Otherwise it is consuming $0.48 \mathrm{~W}$ at standby. The tracker moves once every $20 \mathrm{mins}$ for one millisecond. Each time, lasting only one millisecond means that dual-axis tracking consumes $2.60 \mathrm{mWs}$ every time it moves single-axis tracking multiplying out the $20 \mathrm{~min}$ interval time. This means that the tracker moves approximately 36 times over 12 hours of sunlight. Again, multiplying the values, moving the single-axis tracker consumes $93.6 \mathrm{mWs}$ over the course of a day with 12 hours of sunlight which means it consumes just under $0.01 \mathrm{Wh}$ a day or $0.003416 \mathrm{kWh}$ a year. This is an almost negligible value when the tracker is consuming $0.48 \mathrm{~W}$ for all 24 hours of the day meaning it consumes $11.52 \mathrm{Wh}$ a day or $4.205 \mathrm{kWh}$ a year.

These calculations mean that the net energy gain for the single axis tracking system is $4.20845 \mathrm{kWh}$ less. To get the approximate energy gained by tracking, a model solar panel is selected to make the comparisos. An 80W solar panel is chosen for this comparison because its size and weight are right around the average expected load on the mechanical construction 
of the tracker. This is assuming that the weight of the solar panel is compensated by a counterweight so the mechanical load to the motor has, remained the same. 80 Watts signifies that at maximum solar radiation, which is what was calculated above, then the appropriate value of energy consumed over the year is calculated [11]:

With the net energy calculations, both systems can be compared numerically by using the net energy gain over using just the immobile solar panel. The numbers used are from the 1:1 step size results and all results in this table are average or fair weather conditions over the entire year and each system is using the same identical 80W solar panel:

Therefore we have; $\frac{\text { New-old }}{\text { Old }} \times 100 \%$,

$$
\frac{94.564}{329.566} \times 100 \%=28.69 \%
$$

Percentage Gains of Tracking Systems over a Year $=$ 28.69\%

Here, the clear advantage goes to the dual-axis tracker which offers over a $28 \%$ energy gain over the exact same solar panel in an immobile setup. From the MATLAB graph in table 4, the tracker originally has a draw back over the static mount during the break of day but then this advantage decreases and disappears during the cause of the day showing an absolute advantage of the tracker over the static mount.

\section{CONCLUSIONS}

The Altitude Single-Axis Solar tracker designed and built in this research work show a clear benefit over both immobile tracking systems. The tracker built has a maximum angular error to the sun of $1.5^{\circ}$ in both axes of movement. This value corresponds to a $28 \%$ energy gain over an immobile solar panel setup assuming the solar panels mounted on the tracker and the immobile system are identical $80 \mathrm{~W}$ panels. Furthermore, the single-axis trackers have gains over the immobile system for the entire range of latitudes but these gains were still lower than the dual-axis tracker for all latitudes. Additionally, testing showed that the power used by the tracking system built was much less than the power gained by tracking the sun accurately. This means that if the tracking system were to charge its own batteries, it would be entirely self-sufficient except for maintenance. Perhaps the most important conclusion to be made from this work is that the total cost for this tracking system is very low, less than $\# 90,000$ in parts for each tracker in mass quantities. This means that the system can be built for a very low cost and most importantly; this system would be within the financial reach of many developing countries communities. Based on the simulations, test results and cost analysis this project has met its original goals which is to improve the efficiency of the tracking system by designing a solar tracking rack system.

\section{REFERENCES}

[1] I. Hassan, A. Galadima, and S. Girgisu, "Harnessing solar energy: from past to present" Elixir international Journal, Elixir Space Sci. 65. pp. 19859-19863, 2013.

[2] B. E. Akachukwu, "Prediction of Optimum Angle of Inclination for flat Plate Solar Collector in Zaria, Nigeria." Agricultural Engineering International: CIGR Journal. vol. 13, no.4, 2011. Manuscript No. 1840.

[3] K. Butti, and J. Perlin, A Golden Thread: 2500 Years of Solar Architecture and Technology. Cheshire Books, Frodsham, UK, 289 pp. 1980.

[4] I. U. Chiemeka, and T. C. Chineke, "Evaluating the Global Solar Energy Potential at Uturu, Nigeria", International Journal of Physical Sciences. vol.4 (3) pp.115-119, 2009.

Table 5: Net Energy Generated by 80W Tracking Systems over a Year at average weather condition

\begin{tabular}{lll}
\hline & Fixed mount & Tracking mount \\
\hline Total Voltage & 225.73 & 290.55 \\
Average (voltage) & 16.4807 & 20.75 \\
Average power in 1hr assuming current at 4A $(\mathrm{wH})$ & 64.49 & 83 \\
Power output over 14hrs assuming current at 4A $(\mathrm{wH})$ & 902.9192 & 1162 \\
Power Over 1year $(\mathrm{KwH})$ & 329.566 & 424.130 \\
Gain Difference $(\mathrm{KwH})$ & 94.564 & \\
\hline
\end{tabular}


[5] D. A. Fadare, I. Irimisose, A. O. Oni, and A. Falana, " Modeling Of Solar Energy Potential in Africa Using an Artificial Neural Network", American Journal of Scientific and Industrial Research, Science Huß, Http://Www.Sc ihub.Org/AjsirIssn:2153-649x, 2010.

[6] J. O. Ojosu, "Frequency Distribution Analysis of Daily solar Radiation Measurement at Ikeja (Lagos) for Solar System Design", Nigerian Journal of Renewable Energy. Sokoto Energy Research Centre. vol. 5, pp. 41-44, 1997.

[7] D.B.N. Nnadi, S. E. Oti, and D. C. Ahiabuike, "Mechanical Sun-Tracking Technique Implemented for Maximum Power Point Tracking of a PV System for Effective Energy Supply" Nigerian Journal of Technology
(NIJOTECH) Vol. 33. No. 2, April 2014, pp. 230 $-237$.

[8] Solar Panels Blog / Articles / The Different Kinds of Solar Panel Mounts. April, 2012. www.allsolarpanels.org. Viewed Jan, 2020.

[9] Types of Photovoltaic Solar Mounting Systems 5 Common Mounting Systems. May, 2014. http://www.atlantechsolar.com/photovoltaic_s olar_mounting_systems.html. Viewed Nov, 2019

[10] V. Poulek, and M. Libra, "A Very Simple Solar tracker for Space and Terrestrial applications". Solar Energy Materials and Solar Cells, pp. 99101, 2009.

[11] R. Hamilton, "DC Motor Brush Life". IEEE Transactions on Industrial Applications, vol. 36, no. 6, pp. 1682 - 1687, 2000. 